\title{
Bien común, innovación frugal y empresas con propósito: Movimientos emergentes orientados a la sostenibilidad empresarial
}

\author{
Por: Claudia Ibarra Baidón \\ Académica en la Escuela de Negocios ITESO, Universidad Jesuita de Guadalajara ubicada en Jalisco, México. Coordinado- \\ ra de la Unidad Académica de Administración, Emprendimiento e Innovación. Estudiante de doctorado en la Universidad \\ Nacional Autónoma de México (UNAM), con un protocolo de investigación relacionado a la caracterización del emprendi- \\ miento social sostenible.
}

\section{Resumen}

La iniciativa emprendedora y la formación para la innovación son vectores en los cuales diferentes temáticas de interés global se embeben para llegar a mayores audiencias, tal es el caso de la sostenibilidad y la evaluación de impacto. En el contexto educativo, la educación emprendedora fue vector de la formación para la innovación y actualmente es ya cotidiana la consideración del binomio Innovación y Emprendimiento (Julien y Molina, 2012). Si el interés por desarrollar emprendimiento e innovación, con orientación sostenible para contribuir al bienestar con equidad, está presente en el diálogo cotidiano: ¿Con qué se relacionan los elementos de sostenibilidad en el diseño emprendimientos e innovaciones? ¿Cuáles son algunas de las corrientes o movimientos emergentes que enfatizan la sostenibilidad en el desarrollo de negocios? Este artículo de opinión tiene el objetivo de aportar una breve respuesta inicial a estos cuestionamientos, incentivando al lector a profundizar en el enfoque sostenible de emprendimientos e innovaciones por desarrollar o en proceso. Para tal fin se han recuperado tres movimientos emergentes en Latinoamérica que fueron analizados en un encuentro académico llevado a cabo en abril 2018.

Palabras clave: Emprendimiento sostenible, Innovación sostenible, Sistema B, Innovación Frugal, Economía del Bien Común. n su informe "Nuestro Futuro Común" de 1987, la Asamblea General de las Naciones Unidas definió como desarrollo sostenible el proceso que trata de satisfacer las necesidades económicas, sociales, culturales y ambientales de la actual generación, sin poner en riesgo la satisfacción de las mismas para generaciones futuras. En contraparte, el desarrollo sustentable es el proceso por el cual se preservan, conservan y protegen solo los Recursos Naturales para el beneficio de las generaciones presentes y futuras sin considerar necesidades sociales, políticas ni culturales del ser humano. (Brundtland, 1987). Tomando en cuenta este marco conceptual, sostenibilidad y sustentabilidad no son sinónimos.

En función a lo anterior, este artículo de opinión hará referencia a la sostenibilidad y a la triple cuenta de resultados (social, económico y ambiental), en los contextos de emprendimiento, innovación y negocios.

Durante las tres últimas décadas, las universidades latinoamericanas han impulsado paulatinamente el fomento de la cultura emprendedora y en esa plataforma de formación se han insertado temas como innovación y sostenibilidad, por mencionar algunos. Es cada vez más común escuchar sobre el binomio: innovación y emprendimiento, que busca destacar la importancia de que los emprendimientos incluyan innovación 1 que los diferencie y coadyuve para su permanencia en el mercado. Surge entonces la acepción de: emprendimiento innovador o bien, emprendimiento con innovación (Julien y Molina, 2012). 
¿Con qué se relacionan los elementos de sostenibilidad en el diseño emprendimientos e innovaciones? ¿Cuáles son algunas de las corrientes o movimientos emergentes que enfatizan la sostenibilidad en el desarrollo de negocios? Este artículo de opinión tiene el objetivo de aportar una breve respuesta inicial a estos cuestionamientos, con la intención de incentivar al lector para que profundice en el enfoque sostenible de emprendimientos e innovaciones por desarrollar o en proceso.

Martin y Binder (2017) definen el emprendimiento sostenible como aquel que persigue un enfoque de triple resultado: económico, social y ecológico (éste último se ha mencionado anteriormente como ambiental). Estos autores también identifican que, al desarrollar emprendimientos sostenibles los creadores enfocan primero una doble cuenta de resultados [double bottom line] a través de alguna de estas duplas: social-económica, social-ecológica o económica-ecológica. Conforme avanza el desarrollo de la iniciativa se complementa con el área de resultado/ impacto faltante, para lograr así la triple cuenta de resultados [triple bottom line]. Así entonces, Martin y Binder (2017) proponen que lograr la triple cuenta de resultados es la característica fundamental del emprendimiento sostenible.

Desde las aportaciones de Crane y Matten (2010), la orientación a la sostenibilidad es un objetivo clave en la ética empresarial. En pocas palabras, la sostenibilidad es expresión directa de la ética en los negocios. Diferentes movimientos en el mundo están inquiriendo el desarrollo de emprendimientos, innovaciones y empresas sostenibles, cuyo enfoque considere como elementos clave: la triple cuenta de resultados, la distribución justa de riqueza, la inclusión, la transparen- cia, la regeneración de bienes públicos, la dignidad, por mencionar algunos. A continuación, se describirán brevemente tres movimientos emergentes en América Latina que enfatizan la orientación sostenible y que formaron parte de los contenidos analizados en el pasado "Encuentro Internacional de Emprendimiento Social", que se llevó a cabo en el mes de abril 2018, teniendo como sede el ITESO en Jalisco, México, y en el cual participaron dos colegas de la Universidad Centroamericana José Simeón Cañas (UCA).

\section{Economía del Bien Común2}

Es un movimiento que comenzó en octubre 2010 en España. La Economía del Bien Común (EBC) considera el bien común como el objetivo ético supremo tanto para la sociedad democrática como para la economía y propone el balance del bien común a través de la auto regulación de 20 indicadores en la matriz del bien común (Figura 1), destacando que el bienestar de todas las personas vinculadas a una organización es igual de importante (Felber, 2015).

El enfoque holístico que se propone en esta corriente presenta una respuesta al progresivo empobrecimiento del pensamiento económico-científico que se ha desconectado paulatinamente de sus contextos más importantes: el cultural-ético, el político-democrático y el natural-ecológico. En palabras de Felber (2015) la $E B C$ no es el único modelo económico imaginable para el futuro. Al contrario, pretende ser combinado con modelos y estructuras alternativos enriquecerse y enriquecerlos. Algunos de estos modelos alternativos son: la economía social y solidaria, los bienes comunales, la empresa social, el valor compartido, el valor mixto [blended value], las cadenas híbridas, la economía circular, las empresas B [BCorps], solo por mencionar algunos.

\begin{tabular}{|c|c|c|c|c|}
\hline & DIGNIDAD HUMANA & $\begin{array}{l}\text { SOLIDARIDADY } \\
\text { JUSTICIA SOCIAL }\end{array}$ & $\begin{array}{l}\text { SOSTENIBILIDAD } \\
\text { ECOLOGICA }\end{array}$ & $\begin{array}{l}\text { TRANSPARENCIA } \\
\text { CODECISION }\end{array}$ \\
\hline Proveedores & $\begin{array}{l}\text { A1 Dignidad humana } \\
\text { en la cadena de } \\
\text { suministro }\end{array}$ & $\begin{array}{l}\text { A2 Solidaridad y justicia } \\
\text { social en la cadena de } \\
\text { suministro }\end{array}$ & $\begin{array}{l}\text { A3 Sostenibilidad } \\
\text { ecológica en la cadena } \\
\text { de suministro }\end{array}$ & $\begin{array}{l}\text { A4 Transparencia y } \\
\text { codecisión en la cader } \\
\text { de suministro }\end{array}$ \\
\hline $\begin{array}{l}\text { Dueños, inversionistas } \\
\text { o servicios financieros }\end{array}$ & $\begin{array}{l}\text { B1 Actitud ética en el } \\
\text { manejo de recursos } \\
\text { financieros }\end{array}$ & $\begin{array}{l}\text { B2 Actitud social en el } \\
\text { manejo de recursos } \\
\text { financieros }\end{array}$ & $\begin{array}{l}\text { B3 Inversiones } \\
\text { socioecológicas y uso } \\
\text { apropiado de fondos }\end{array}$ & $\begin{array}{l}\text { B4 Propiedad y } \\
\text { codecisión }\end{array}$ \\
\hline Empleados & $\begin{array}{l}\text { C1 Dignidad humana } \\
\text { en el puesto de trabajo }\end{array}$ & $\begin{array}{l}\text { C2 Configuración de } \\
\text { los contratos de trabajo }\end{array}$ & $\begin{array}{l}\text { C3 Fomento del } \\
\text { comportamiento } \\
\text { ecológico de las } \\
\text { personas empleadas }\end{array}$ & $\begin{array}{l}\text { C4 Codecisión intema } \\
\text { y transparencia }\end{array}$ \\
\hline $\begin{array}{l}\text { Clientes y socios de } \\
\text { negocio }\end{array}$ & $\begin{array}{l}\text { D1 Relaciones éticas } \\
\text { con la clientela }\end{array}$ & $\begin{array}{l}\text { D2 Cooperación y } \\
\text { solidaridad con otras } \\
\text { empresas }\end{array}$ & $\begin{array}{l}\text { D3 Impacto ecológico } \\
\text { por la utilización y gestión } \\
\text { de los residuos de los } \\
\text { productos y servicios }\end{array}$ & $\begin{array}{l}\text { D4 Participación de la } \\
\text { clientela y transparenc } \\
\text { del producto }\end{array}$ \\
\hline $\begin{array}{l}\text { Entorno social } \\
\text { ambiental }\end{array}$ & $\begin{array}{l}\text { E1 Significado e } \\
\text { impacto social de los } \\
\text { productos y servicios }\end{array}$ & $\begin{array}{l}\text { E2 Contribución a la } \\
\text { comunidad }\end{array}$ & $\begin{array}{l}\text { E3 Reducción de los } \\
\text { impactos ambientales }\end{array}$ & $\begin{array}{l}\text { E4 Transparencia y } \\
\text { codecisión social }\end{array}$ \\
\hline
\end{tabular}

Figura 1. Matriz del bien común sobre la que se aplica el balance de bien común. Elaboración propia basada Felber (2015) con información disponible en: https://cooperaccion.es/la-matriz-del-bien-comun-5-0 
Innovación Frugal

La innovación frugal es una estrategia de innovación para mercados emergentes donde un producto, servicio o proceso le da solución a una necesidad que emerge desde la base de la pirámide poblacional y cuyas características son: 1) maximizar el valor agregado de la solución, minimizando el uso de energía capital, tiempo y complejidad; 2) utilizar tecnologías apropiadas al contexto; 3 ) quienes viven el problema están al centro del diseño de la solución. Innovación Frugal no es algo barato o simplista, en realidad se trata de un tipo de innovación que da primacía al ingenio sobre el capital, que toma en cuenta el contexto de carencia en el que se está buscando crear valor y considera la colaboración en alianzas para lograr precios accesibles. Es justo una corriente que va en sentido inverso a la sobre-ingeniería de productos que está vinculada al consumismo extremo y a la sobre explotación de recursos naturales. Sus raíces como corriente están en la India donde se reconoce como Jugaad3. (Báez, 2018). Rossetto et al., (2017) proponen tres dimensiones para la innovación frugal: 1) reducción substancial de costos, 2) concentración en las funcionalidades centrales esenciales y en el rendimiento, 3) creación de un ecosistema frugal. Estos autores buscan desarrollar un instrumento de medición para estas dimensiones, con las que proponen un enfoque sostenible en el desarrollo de nuevos productos.

\section{Sistema B4}

Con la misión de construir ecosistemas favorables para Empresas B [BCorps] y otros actores económicos que utilizan la fuerza del mercado para dar solución a problemas sociales y ambientales, surge Sistema B en Estados Unidos en el año 2006 y en el año 2012 Latinoamérica. Las Empresas B son organizaciones con propósito que ofrecen retornos financieros para sus accionistas, al mismo tiempo que crean impacto positivo en la sociedad y en la naturaleza. Sus accionistas se han comprometido legalmente a tener impacto positivo en la sociedad y en la naturaleza utilizando como medio su negocio, gestionando impactos sociales y ambientales con el rigor y enfoque de los asuntos financieros. La certificación B está basada en la evaluación de impacto $B$ [B-assessment] 5 que analiza cinco áreas: clientes, gobernanza, trabajadores, comunidad y medio ambiente. (Honeyman, 2014). A diferencia de otros esquemas de certificación, este está basado en intencionalidad antes que en cumplimiento indispensable. Un elemento diferenciador de esta propuesta es que la orientación a la sostenibilidad que propone es legalmente vinculante. Esto quiere decir que se requiere una modificación de estatutos aceptada por los accionistas, como expresión de compromiso para ser una Empresa B.

\section{Un llamado a la acción}

Esta es una invitación para analizar estos y otros movimientos o corrientes de orientación sostenible en los negocios, en la búsqueda de abstraer elementos que deberían estar considerándose en las aulas y en los laboratorios, donde estudiantes, profesores y actores de la sociedad, colaboran desarrollando soluciones y proyectos. Si algunos de estos elementos están presentes desde la fase de diseño, crece la posibilidad de diferenciar e innovar el emprendimiento en desarrollo, justo desde su orientación sostenible.

\section{Referencias}

Brundtland, G. H. (1987). Our Common Future: Report of the World Commission on Environment and Development. United Nations Commission (Vol. 4). https://doi.org/10.1080/07488008808408783

Julien, P. \& Molina, R. (2012). La definición de emprendimiento. En Julien, P. (Ed. Pearson Educación), Una teoría sobre el emprendimiento regional en la economía del conocimiento (pp. XII). México: Pearson Educación.

OCDE. (2005). Manual de Oslo: una guía para la recolección e interpretación de datos sobre innovación. EUROSTAT. Resumen disponible, recuperado de: http://portal.uned.es/portal/page?_pageid=93,23280929\&_dad=portal\&_schema=PORTAL Martin, F., \& Binder, J. (2017). Sustainable Entrepreneurship: A Convergent Process Model. Business Strategy and the Environment, 26, 1-17. doi:10.1002/bse. 1887

Crane, A., \& Matten, D. (2010). Business Ethics. Oxford: Oxford University Press.

Felber, C. (2015). La Economía del Bien Común (Segunda ed.). Barcelona, España: DEUSTO.

Honeyman, R. (2014). The B Corp Handbook: How to Use Business as a Force for Good (Exerpt). B lab. Oakland CA: Berrett-Koehler Publishers Inc. Retrieved from http://www.bcorporation.net/handbook

Báez, A. (2018). Innovación Frugal. En: Encuentro Internacional de Emprendimiento Social llevado a cabo en el ITESO, Jalisco México. Disponible en: https://www.youtube.com/watch?v=2Fz7HcJZRjw

Rossetto, D. \& Borini, F. \& Carlos Bernardes, R. \& Frankwick, G. (2017). A new scale for measuring frugal innovation: The first stage of development of a measurement tool. VI Simposio Internacional de Gestão de Projetos, Inovação e Sustentabilidade - SINGEP, At São Paulo, SP, Brazil. 